\title{
Comunicação na sala de aula: a perspetiva do ensino exploratório da matemática ${ }^{1}$
}

\author{
António Guerreiro² \\ Rosa Antónia Tomás Ferreira ${ }^{3}$ \\ Luís Menezes ${ }^{4}$ \\ Maria Helena Martinho5
}

\begin{abstract}
Resumo: Este artigo procura responder ao desafio de pensar a comunicação que tem lugar na aula de Matemática. Contrariamos a visão simplista da comunicação como instrumento de transferência de conhecimento (do professor para os alunos) para assumirmos a comunicação como processo de interação, no qual o conhecimento matemático é socialmente construído. Esta visão da comunicação na aula de Matemática representa uma aproximação aos processos de produção e comunicação de conhecimento matemático que têm lugar no campo científico e no agir diário das comunidades humanas (quando lidam com ideias matemáticas). Para que isso ocorra, são exigidas mudanças no ensino, particularmente no papel do professor e no dos alunos. O ensino exploratório da Matemática é apresentado como um meio privilegiado do professor, apoiado num conjunto de ações comunicativas fundamentais, criar ambientes de aprendizagem produtivos, que, envolvendo o trabalho com tarefas matemáticas desafiantes, a sua resolução e discussão, culminam na institucionalização de conhecimento matemático.
\end{abstract}

Palavras-chave: Comunicação na sala de aula de Matemática; Ensino exploratório da Matemática; Ações comunicativas do professor.

\section{Classroom communication: The perspective of inquiry-based mathematics teaching}

Abstract: This paper aims at answering to the challenge of thinking about the communication that occurs in the mathematics classroom. We disagree with the simplistic view of communi-

$1 \quad$ Nota dos editores: A revista Zetetiké, por respeitar as diferenças linguísticas que ainda persistem após o acordo ortográfico entre os países de língua portuguesa, optou por publicar este artigo na linguagem original dos autores.

2 Doutor em Didática da Matemática pela Universidade de Lisboa. Professor da Escola Superior de Educação e Comunicação, Universidade do Algarve, Portugal, e investigador da Unidade de Investigação e Desenvolvimento em Educação e Formação, Instituto de Educação, Universidade de Lisboa, Portugal. Email: aguerrei@ualg.pt.

3 Doutora em Educação Matemática por Illinois State University, EUA, Professora da Faculdade de Ciências da Universidade do Porto, Portugal, e investigadora do Centro de Matemática da Universidade do Porto. Email: rferreir@fc.up.pt.

4 Doutor em Didática da Matemática pela Universidade de Lisboa. Professor da Escola Superior de Educação de Viseu, Portugal, e investigador do Centro de Estudos em Educação, Tecnologias e Saúde. Email: menezes@esev.ipv.pt.

5 Doutora em Didática da Matemática pela Universidade de Lisboa. Professora da Universidade do Minho, Portugal, e investigadora do Centro de Investigação em Educação, Instituto de Educação da Universidade do Minho. Email:mhm@ie.uminho.pt. 
cation as a tool for knowledge transfer (from teacher to students); instead, we assume communication as a process of interaction, in which mathematical knowledge is socially constructed. Such a vision of communication in the mathematics classroom resonates with the processes of production and communication of mathematical knowledge that take place in the scientific field and the human community's daily acting (when using mathematical ideas). Thus, changes are needed in mathematics teaching, particularly regarding the teacher's and the students' roles. Inquiry-based mathematics teaching is appointed as a privileged way to, supported by a set of fundamental communicative actions, create productive learning environments, which involve students' work in challenging mathematical tasks, solving them and discussing the approaches taken, and culminate in the institutionalization of mathematical knowledge.

Keywords: Communication in the mathematics classroom; Inquiry-based mathematics teaching; Teachers' communicative actions.

\section{Introdução}

Este artigo é um ensaio sobre o papel da comunicação na aula de Matemática, numa perspetiva de valorização da interação comunicativa entre os alunos e entre estes e o professor. Defendemos a ideia de que pensar sobre a aula de Matemática pressupõe pensar sobre o papel que a comunicação desempenha nessa aula. Argumentamos que o tipo de comunicação matemática desenvolvida na sala de aula influencia fortemente o ensino-aprendizagem da Matemática. Este pensamento está presente nas preocupações dos educadores matemáticos que estudam a ecologia da aula de Matemática e na prática profissional do professor, nas suas conceções sobre o ensino e a aprendizagem, quando ensina Matemática. Os modelos de ensino concretizados pelo professor sustentam-se em distintas perspetivas de comunicação: um ensino com características expositivas equaciona a comunicação como instrumento de verbalização e transmissão do conhecimento; por sua vez, o ensino com uma forte vertente de interação social apoia-se na comunicação como construção partilhada do conhecimento matemático.

Ensinar, sendo uma atividade multifacetada, tem como um dos seus principais objetivos levar o aluno a desenvolver o seu conhecimento matemático. O ensino exploratório da Matemática (inquiry-based mathematics teaching) corresponde a uma abordagem ao ensino, em que a comunicação se sustenta em processos de discussão e de negociação, os quais dão corpo a situações de produção e consolidação do conhecimento matemático por parte dos alunos. Neste sentido, a comunicação não é apenas um instrumento de verbalização das ideias matemáticas, mas assume também uma natureza de negociação de significados com vista à construção do conhecimento matemático.

Nestes termos, o argumento que desenvolvemos neste texto de inter-relação entre a comunicação e as práticas de ensino, particularmente na valorização da comunicação como interação no ensino exploratório, leva-nos a discutir diferentes 
perspetivas sobre a comunicação na aula de Matemática e a sua relação com os processos de desenvolvimento do conhecimento matemático. Assumindo que o professor é um organizador de ambientes de aprendizagem, analisamos o seu papel na promoção da comunicação, focando a utilização de algumas ferramentas discursivas que tem à sua disposição. Em seguida, posicionamo-nos face a modelos de ensino da Matemática que melhor desencadeiam nos alunos a aprendizagem da Matemática com compreensão, onde a comunicação, através da discussão de ideias matemáticas, é o elemento estruturante do processo de ensino-aprendizagem. Por último, particularizamos a natureza das interações nas discussões matemáticas coletivas na sala de aula por considerarmos um momento essencial, em termos comunicativos, no confronto de opiniões e no desenvolvimento das aprendizagens em Matemática.

\section{Perspetivas sobre a comunicação na aula de matemática}

O ensino-aprendizagem da Matemática que ocorre numa sala de aula é um processo eminentemente comunicativo. Esta comunicação pode ser conduzida tendo por base diversas perspetivas teóricas, que têm consequências na relação entre o professor e os alunos e na forma como o conhecimento matemático é ensinado e aprendido. Nesta secção, analisamos três dessas perspetivas: (i) comunicação como processo de transmissão de informação; (ii) comunicação como processo semiótico; e (iii) comunicação como processo de interação social.

\section{Perspetiva da comunicação como processo de transmissão de informa-} ção. Os processos de comunicação entre os indivíduos, através de atos discursivos, incluem silêncios, gestos e comportamentos, olhares e posturas, ações e omissões (Rodrigues, 1990). Estes processos resultam de um ato voluntário, em que dois sujeitos decidem pôr-se em contacto ou um decide fazê-lo e o outro aceita (Sfez, 1991), desenvolvendo-se numa lógica de estímulo que provoca uma reação através de um processo linear e unidirecional. Para os defensores dos modelos de comunicação como um processo de transmissão de mensagens centrado no poder da fonte de informação (Lasswell, 2009), a comunicação pode ser equacionada de diversas formas: ao nível da precisão com que se processa a transmissão de informação do emissor para o recetor; ao nível da exatidão do significado das informações que são transferidas até ao destinatário; e ao nível da capacidade das informações influenciarem o comportamento do destinatário no processo de comunicação.

A valorização da interação social, entendida como o "processo pelo qual uma pessoa se relaciona com outras ou afeta o comportamento, estado de espírito ou reação emocional de outra” (Fiske, 2005, p. 15), questiona a linearidade do processo de comunicação ao examinar a natureza dos processos de interação e a questão da 
significação e da estrutura interna da mensagem. Na conversação ou no diálogo, os papéis de emissor e de recetor sobrepõem-se nas mesmas pessoas (Lasswell, 2009), gerando uma natureza circular ou helicoidal ao modelo de comunicação. Segundo a perspetiva da comunicação como transação de mensagens entre duas ou mais pessoas, o ensino da Matemática é caracterizado pelo diálogo entre os alunos e o professor, no desenvolvimento de estratégias de comunicação que minimizem a diferença entre o que se ensina e o que se aprende e que favoreçam os processos de clarificação do entendimento da informação (Antão, 2001).

Perspetiva da comunicação como processo semiótico. O estudo da comunicação numa perspetiva semiótica valoriza a significação, a interpretação e o valor informativo das mensagens que os sujeitos trocam entre si (Guerreiro, 2011). As mensagens são entendidas como signos ou uma organização complexa de signos, isto é, como estímulos com significados para as pessoas, formados através dos processos de pensamento (Eco, 2002; Freixo, 2006). A semiótica procura compreender o modo como a linguagem se torna significativa e como é que esse significado pode ser comunicado em sociedade, assumindo o estudo dos signos, dos sistemas organizadores de signos e da cultura no interior da qual estes sistemas se encontram organizados. O signo é entendido como uma forma de expressão portadora de uma significação, dependente da sua natureza, do contexto da sua manifestação e da cultura e preocupações do recetor (Eco, 1997; Joly, 2005).

Na perspetiva semiótica, a Matemática é um sistema de comunicação constituído por signos, social e historicamente determinados (Corrêa, 2005). A evocação dos objetos matemáticos, que não têm uma natureza real, depende do recurso a representações dentro de uma semiótica específica da linguagem matemática, não sendo possível aceder aos objetos matemáticos sem mobilizar as representações semióticas (Duval, 2006). A compreensão da complexidade das aprendizagens deve ter em conta a importância e a variedade das representações semióticas utilizadas em Matemática (Duval, 2006) e a compreensão da natureza dos conceitos e proposições matemáticas e da sua relação com os contextos (Godino, 2002).

Perspetiva da comunicação como processo de interação social. A comunicação é também entendida como um processo social onde os intervenientes interagem, trocando informações, influenciando-se reciprocamente na construção de significados (Menezes, Tomás Ferreira, Martinho \& Guerreiro, 2014). Na perspetiva interacionista, a sociedade é concebida como um processo de interação tecido pela comunicação, a qual tem a função de criar e manter consensos e entendimentos entre os indivíduos, sendo vista como um processo de partilha de significados. A interação social define-se como um processo pelo qual cada sujeito é capaz de se colocar no lugar do outro, construindo a sua própria identidade (Beaudichon, 2001). É em interação que o sujeito aprende a ver-se com os olhos do outro numa ação de 
complementaridade e de reconhecimento mútuo. Nesta perspetiva, os atores formam uma "comunidade de comunicação sob obrigação de cooperação" (Habermas, 1998, p. 276).

Na perspetiva interacionista, o conhecimento emerge de uma prática discursiva que se desenvolve na sala de aula, na instituição escolar e na sociedade, decorrente de processos coletivos de comunicação e de interação (Sierpinska, 1998). O ensino-aprendizagem da Matemática converte-se num processo interativo e reflexivo entre o professor e os alunos, guiado por regras e normas sociais, negociadas e aceites, que emergem da própria prática e regulam a participação dos intervenientes na sala de aula (Bishop \& Goffree, 1986; Godino \& Llinares, 2000).

\section{Ações comunicativas do professor na sala de aula}

São várias as ações comunicativas do professor na aula, mas a investigação tem destacado quatro em particular: (i) explicar; (ii) questionar; (iii) ouvir; e (iv) responder (e.g., Cengiz, Kline \& Grant, 2011; Leinhardt, 2001; Menezes et al., 2014; Nicol, 1999; Tomás Ferreira, 2005). Detemo-nos aqui, brevemente, sobre cada uma delas, procurando destacar o papel do professor.

Explicar. De acordo com Bishop e Goffree (1986), explicar envolve essencialmente fazer conexões entre a ideia que está a ser apresentada e ideias supostamente partilhadas por quem recebe a explicação. Podemos distinguir alguns tipos de explicações (Leinhardt, 2001) consoante a audiência a que se destina e o aspeto que gera a necessidade da sua existência: explicações comuns, explicações disciplinares, explicações instrucionais e autoexplicações.

As explicações comuns decorrem da resposta a um aspeto, relativamente simples, do quotidiano que esteja a ser discutido. As explicações disciplinares relacionam-se com os conteúdos disciplinares, respondendo "a questões não contextualizadas, válidas em qualquer momento ou lugar, e revestindo-se de algum formalismo" (Menezes et al., 2014, p. 142). As explicações instrucionais são as que mais se relacionam com o ensino, uma vez que o seu objetivo é comunicar um conteúdo a alguém; podem ser individuais ou construídas coletivamente, sendo particularmente importantes os convites que o professor faz aos alunos para produzirem explicações e as partilharem entre todos. As autoexplicações são as que se manifestam quando a própria pessoa se coloca questões e lhes responde - o pensar alto (Leinhardt, 2001).

Questionar. Questionar é uma ação comunicativa do professor largamente presente nas aulas. Entendemos as perguntas do professor de forma lata, como pedidos de informação dirigidos aos alunos, podendo ter ou não a forma interrogativa (Menezes, Guerreiro, Martinho \& Tomás Ferreira, 2013). Tal como na vida quotidiana, o professor pode colocar questões aos alunos que correspondem a 
pedidos genuínos de informação - as perguntas genuínas (Ainley, 1988). Mas as perguntas genuínas não são as que estão mais presentes na sala de aula. Em geral, os propósitos das perguntas do professor são verificar conhecimentos, focar ideias ou estratégias ou inquirir sobre o pensamento matemático do aluno (Menezes et al., 2013). Distinguimos, assim, três tipos principais de perguntas do professor: perguntas de verificação, de focalização e de inquirição (Ainley, 1988; Mason, 1998, 2000; Menezes, 1995).

As perguntas de verificação (ou perguntas teste) pretendem avaliar os conhecimentos dos alunos, comparando-os com os conteúdos matemáticos trabalhados pelo professor, estabelecer conexões entre ideias matemáticas e regular o comportamento dos alunos em sala de aula (Ainley, 1988; Mason, 1998, 2000). As perguntas de focalização e as perguntas de inquirição permitem desenvolver a compreensão e o conhecimento matemático dos alunos. O propósito das perguntas de focalização é centrar a atenção dos alunos num aspeto específico que o professor quer ver melhor discutido ou que ele entende ser particularmente complexo para os alunos. Se o professor extremar demasiado o questionamento de focalização, através de perguntas sucessivas de decrescente nível de complexidade, este tipo de questões não contribui para uma aprendizagem com compreensão; pelo contrário, se as perguntas de focalização direcionarem a atenção do aluno para o seu próprio pensamento, numa lógica metacognitiva, então elas apoiam uma aprendizagem significativa da matemática (Bauersfeld, 1994; Mason, 2010; Menezes, 1995; Voigt, 1985). O propósito das perguntas de inquirição é aceder ao pensamento matemático dos alunos e desafiá-los na busca de conhecimento matemático novo. Pedidos para explicar raciocínios, clarificar conceitos ou procedimentos, relacionar ideias ou processos, justificar estratégias ou refletir sobre o que foi feito são exemplos de ações comunicativas do professor sustentadas em perguntas de inquirição.

Ouvir. Da mesma forma que o professor pode fazer perguntas aos alunos com propósitos diversos, também os pode ouvir de modos diferentes, dependendo do papel que atribui ao ato de ouvir, papel esse que reflete a visão que tem acerca do que significa ensinar e aprender Matemática. $O$ professor pode ouvir os alunos predominantemente para avaliar os seus conhecimentos contra um conjunto pré-estabelecido de ideias ou respostas - ouvir avaliativo ou diretivo - mas pode também ter como intenção frequente compreender as ideias e o pensamento matemático dos alunos - ouvir interpretativo ou observacional. Um ouvir avaliativo está associado a uma monopolização do discurso por parte do professor, ignorando as contribuições dos alunos para esse mesmo discurso. Por seu turno, um ouvir interpretativo está associado a pedidos frequentes de explicação ou justificação, consequência das várias oportunidades de interação que o professor proporciona aos alunos (Callahan, 2011; Davis, 1996, 1997). 
O professor pode ainda tendencialmente ouvir os alunos para conhecer e avaliar como eles estão a pensar matematicamente com o propósito simultâneo de informar e orientar a sua prática letiva - ouvir globalizante (ou transformativo, hermenêutico ou responsivo) (Callahan, 2011; Coles, 2001; Davis, 1997; Tomás Ferreira, 2005). Este modo de ouvir, que inclui características dos dois modos anteriores, está associado a um ambiente de aprendizagem que se apoia em tarefas desafiantes e em discussões matemáticas coletivas, em que os alunos contribuem de forma efetiva e determinante para o discurso (Davis, 1997; Tomás Ferreira, 2005). Assim, o ouvir globalizante é "determinante para melhorar a sua [dos alunos] compreensão matemática, proporcionando contextos favoráveis a uma avaliação das aprendizagens de natureza reguladora e permitindo apoiar e desenvolver [essas aprendizagens] " (Menezes et al., 2014, p. 146). O modo de ouvir globalizante requer do professor uma visão do ensino e da aprendizagem da Matemática assente na compreensão de conceitos e procedimentos e na resolução de problemas, exige do professor um conhecimento matemático vasto e flexível, e demanda que o ambiente da sala de aula seja pautado por tarefas desafiantes e discussões matemáticas produtivas (Tomás Ferreira, 2005).

Responder ou reagir. Responder, ou reagir, aos alunos é um ato comunicativo do professor que procede sempre de uma intervenção ou contributo para o discurso dos primeiros. As respostas ou reações do professor tanto podem promover comportamentos mais autónomos nos alunos como perpetuar a sua dependência do próprio professor. Uma resposta pode ser direta, pode conter uma explicação, pode fornecer informação, pode validar (ou evitar fazê-lo) uma resposta de um aluno a uma pergunta colocada, pode promover o confronto entre respostas dos alunos, etc. (Nicol, 1999). A adequação de uma resposta depende da pergunta ou solicitação que lhe deu origem e da forma como o professor ouviu a intervenção do aluno. Por exemplo, uma resposta direta de cariz avaliativo pode ser adequada a uma pergunta de verificação mas o redirigir da validação matemática para outro aluno ou para a turma também pode ser promissora (Nicol, 1999; Tomás Ferreira, 2005).

As perguntas de focalização e de inquirição já exigem do professor uma reação diferente às contribuições dos alunos, sob pena de perderem o seu propósito. Por exemplo, solicitar a terceiros explicações sobre estratégias apresentadas por alunos, pedir aos alunos que elaborem sobre respostas que os mesmos deram, ou redirigir questões para a turma, são exemplos de respostas ou reações dos professores adequadas aos contributos dos alunos procedentes de perguntas de focalização ou de inquirição. Responder às intervenções dos alunos acarreta vários desafios entre os quais evitar fornecer-lhes demasiada informação que possa diminuir o nível cognitivo da tarefa ou questão em causa, e transformar respostas erradas ou incompletas em objetos de discussão e pontos de partida para a ultrapassagem de obstáculos (Nicol, 1999; Tomás Ferreira, 2005). 
As ações comunicativas do professor que abordámos aqui estão todas inter-relacionadas e dependem do contexto mais amplo em que se dá a interação. Contudo, optámos por analisá-las em separado para melhor podermos realçar o papel do professor em cada uma delas. Há certamente associações entre estas ações comunicativas que são facilmente identificáveis; por exemplo, um predomínio de perguntas de verificação relaciona-se com uma tendência clara do professor em ouvir os alunos de forma avaliativa e em responder-lhes de maneira mais ou menos direta e validando, ou não, as suas ideias. Da mesma forma, numa sala de aula caracterizada pela presença regular de perguntas de inquirição também se identifica um ouvir do professor tendencialmente globalizante, sendo as suas reações às intervenções dos alunos diversificadas e centradas na promoção de uma aprendizagem com compreensão e autonomia.

\section{Comunicação no ensino exploratório da Matemática}

A forma como se conceptualiza o papel da comunicação na construção do conhecimento matemático tem consequências no plano didático. Se aceitarmos que a comunicação é um veículo ao serviço da transmissão do conhecimento, do professor para os alunos, tendemos a defender o chamado ensino direto (Ponte, 2005). Se considerarmos que a comunicação é um processo complexo e multidimensional através do qual os alunos em interação entre si e com o professor constroem e compartilham significados para as ideias e os procedimentos matemáticos, tendemos a adotar o designado ensino exploratório (Ponte, 2005).

$\mathrm{O}$ ensino direto da Matemática pode ser expresso pela metáfora o professor fala e os alunos ouvem (Sierpinska, 1998), ou seja, este ensino tem uma natureza fortemente unidirecional, baseada numa comunicação com características transmissivas. Apesar de esta abordagem ao ensino ser claramente ineficaz em termos dos resultados na aprendizagem da Matemática (Ponte, 2005), continua a ser muito comum em muitas salas de aula, talvez por ser cómoda para o professor, falsamente segura e previsível, e basear-se numa conceção, algo generalizada, de comunicação como transferência de conhecimento do professor para os alunos.

O ensino exploratório da Matemática pode ser representado pela metáfora professor e alunos dialogam (Sierpinska, 1998), ou seja, este ensino tem uma natureza multidirecional e baseia-se numa visão de comunicação assente na interação social. No ensino exploratório, a construção do conhecimento é um processo pessoal que se efetiva na interação com os outros, ou seja, o conhecimento emerge na interação social, resultado de processos de negociação de significados (Bishop \& Goffree, 1986), nos quais o professor desempenha um papel relevante de suporte. Este processo de construção é marcado e personalizado por cada um dos alunos, dado que estes 
têm conhecimentos e experiências prévias que são próprias e singulares (Menezes et al., 2014).

Apesar de o ensino exploratório produzir bons resultados em termos da aprendizagem da Matemática, tanto ao nível dos conhecimentos como das capacidades matemáticas, não constitui uma prática largamente adotada pelos professores, talvez porque é bastante exigente para estes e, por vezes, graças aos continuados contributos dos alunos na aula, pouco previsível no seu curso (Menezes, Oliveira \& Canavarro, 2015). Embora o ensino exploratório da Matemática possa assumir diversas formas e matizes, há um conjunto de ingredientes essenciais e formas próprias de os combinar, que dão corpo a aulas de Matemática ricas, em que professor e alunos estão muito ativos (Canavarro, 2011; Stein \& Smith, 1998; Stein, Engle, Smith \& Hughes, 2008).

As tarefas matemáticas ricas e desafiantes, pontos de partida para a atividade dos alunos com compreensão, são um ingrediente essencial para uma aprendizagem significativa da Matemática (Stein \& Smith, 1998). Nos níveis de escolaridade iniciais, as tarefas matemáticas estão habitualmente associadas a materiais didáticos que cumprem a função de ajudar a representar as ideias matemáticas em jogo na situação apresentada. A cooperação dos alunos durante a sua atividade, nomeadamente no trabalho em pequenos grupos, é um elemento importante no ensino exploratório, favorecendo a comunicação entre os alunos. A profusa atividade dos alunos, tanto nos grupos como no plenário da turma, não substitui, muito pelo contrário, a atividade do professor (Canavarro, 2011).

No ensino exploratório, o professor ouve muito os alunos porque quer dialogar com eles (Menezes et al., 2014). Como já referimos, só dessa maneira consegue perceber que ideias matemáticas têm os alunos, como estão a pensar e que eventuais erros e dificuldades estão a sentir. Porque nem sempre os alunos são espontâneos nas suas intervenções, a pergunta, matizada com diferentes propósitos, é um ato discursivo a que o professor pode lançar mão para dinamizar as interações comunicativas.

Uma aula de ensino exploratório da Matemática organiza-se em diversas fases, nas quais os alunos são confrontados com tarefas matemáticas que têm como objetivo principal a introdução e/ou aprofundamento de conteúdos matemáticos e o desenvolvimento de capacidades matemáticas como o raciocínio, a comunicação e a resolução de problemas matemáticos (Menezes et al., 2015; Stein et al., 2008). Canavarro, Oliveira e Menezes (2012) propõem quatro fases para organizar uma aula de ensino exploratório da Matemática, as quais designam por: (i) introdução da tarefa; (ii) realização da tarefa; (ii) discussão da tarefa; e (iv) sistematização das aprendizagens matemáticas. 
Na primeira fase da aula, de "introdução da tarefa”, o professor apresenta aos alunos a tarefa, explicando o que espera deles. Menezes et al. (2015) identificam nesta fase da aula diversas intenções de o professor, nomeadamente, garantir a apropriação da tarefa pelos alunos e promover a adesão dos alunos à tarefa proposta. Estas intenções concretizam-se através de um conjunto de ações do professor com uma acentuada dimensão comunicativa, como sejam, familiarizar os alunos com o contexto da tarefa, esclarecer a interpretação da tarefa e estabelecer objetivos. Para isso, os professores são levados a dar explicações instrucionais e também a colocar questões de verificação para despistar possíveis dificuldades dos alunos, sobretudo relacionadas com a compreensão da tarefa.

Na fase seguinte da aula, "realização da tarefa”, os alunos atacam a tarefa, habitualmente em pequenos grupos, tendo oportunidade de trocar entendimentos, comunicando as suas ideias e processos de resolução. Este é o momento da aula em que o professor ouve e observa os alunos para monitorizar o rumo dos acontecimentos (ações para as quais um ouvir globalizante é essencial). Pode também colocar questões (sobretudo de focalização e inquirição) ou responder aos alunos através de comentários. Nesta fase da aula, o professor procura, apoiado nas ações comunicativas indicadas, garantir o desenvolvimento da tarefa pelos alunos, manter o desafio cognitivo da tarefa e a autonomia dos alunos, e organizar a discussão a fazer de seguida (Menezes et al., 2015).

A aula prossegue com a fase de "discussão da tarefa", em que o professor organiza as apresentações do trabalho matemático realizado pelos grupos para serem comunicadas e discutidas em grande grupo. Tendo em conta os objetivos a que se propôs, o professor promove a audição e discussão do trabalho de grupos de alunos (evitando repetições nas apresentações), deixando para o fim o(s) grupo(s) que mais avançaram na generalização e/ou na resolução da tarefa (Menezes et al., 2015). Nesta fase da aula, destaca-se no professor a intenção de promover a qualidade matemática das discussões dos alunos, solicitando explicações e justificações (Cengiz et al., 2011; Ruthven, Hofmann, \& Mercer, 2011; Stein et al, 2008). Para isso, é muito importante ouvir os alunos (ouvir globalizante) e, como forma de reagir, formular perguntas (sobretudo de inquirição, para levar os alunos a explicar e a justificar ideias e procedimentos matemáticos, bem como estabelecer conexões entre as várias ideias matemáticas ou estratégias de resolução que vão sendo avançadas).

A última fase da aula, "sistematização das aprendizagens matemáticas”, é essencial para a construção de conhecimento matemático. Nesta fase, o professor assume mais o discurso, procurando institucionalizar ideias ou procedimentos relativos a tópicos e procedimentos matemáticos, suscitados pela exploração da tarefa, sobretudo durante a discussão coletiva do trabalho dos alunos, e estabelecer conexões com aprendizagens anteriores. Para isso, o professor é, sobretudo, levado 
a dar explicações instrucionais, procurando estabilizar processos de negociação de significados matemáticos. A avaliação da construção do conhecimento pelos alunos, culminando um processo comunicacional fortemente interativo e socialmente partilhado (próximo do que acontece em muitos contextos de aprendizagem fora da sala de aula), é acompanhada pelo professor através de perguntas de verificação e do ouvir globalizante.

\section{Discussões matemáticas coletivas na sala de aula}

A discussão coletiva na aula de ensino exploratório da Matemática, sendo um ponto alto na fase pós trabalho dos grupos, pode estar presente também nas outras fases da aula, em micro episódios de discussão. Por exemplo, ao detetar uma dúvida ou dificuldade generalizada nos alunos, o professor pode sentir necessidade de parar momentaneamente o trabalho dos grupos e dinamizar uma pequena discussão em plenário, visando a clarificação de entendimentos. Por se tratar de um elemento distintivo e fulcral do ensino exploratório da Matemática face a outros tipos de ensino, abordamos, a seguir, a discussão coletiva como um processo e um instrumento privilegiados de produção de conhecimento na aula de Matemática, e não simplesmente como uma das fases da aula exploratória.

Por discussão matemática na sala de aula entendemos o processo de interação e partilha de conteúdos matemáticos num ambiente comunicativo rico, intencionalmente construído, visando suportar o desenvolvimento das aprendizagens em Matemática. Segundo Pirie e Schwarzenberg (1988), trata-se de uma conversa com propósito sobre um assunto matemático na qual os alunos dão contributos genuínos e interagem entre eles e com o professor. Dillon (1994) vai no mesmo sentido, acentuando que se trata de um tipo de conversação no qual se avançam e examinam diferentes propostas acerca de um problema, podendo estas propostas ser compreensões, factos, sugestões, experiências ou algo similar que possa ser analisado como uma contribuição para a sua resolução.

A discussão coletiva, como acontece no ensino exploratório, pressupõe uma forma de organização diferente da de uma aula de ensino direto. Assim, pretende-se criar uma comunidade matemática de discurso (Sherin, 2002) assente no trabalho efetivo com ideias matemáticas, numa postura ativa dos alunos e nas capacidades de estes utilizarem o seu pensamento crítico e reflexivo na expressão e construção do seu próprio universo matemático. Para isso, o aluno é encorajado a tomar posições, argumentar sobre elas, defendê-las e procurar convencer os outros do seu ponto de vista (Stein, 2001). Deste modo, o aluno habitua-se a explicar e questionar raciocínios e estratégias de resolução de problemas ou investigações, a identificar e corrigir incorreções e a ganhar confiança em si mesmo (Hintz, 2011). 
Orquestrar discussões matemáticas produtivas é um empreendimento exigente nas aulas de ensino exploratório da Matemática, sendo o papel do professor extremamente relevante para esse desiderato (Stein et al., 2008). A discussão matemática na sala de aula não ocorre normalmente de forma espontânea, sendo necessário induzi-la. Lampert (2001) analisa possíveis estratégias, referindo que uma delas consiste em iniciar a discussão por uma questão aberta, convidando os alunos a pronunciarem-se. $\mathrm{O}$ objetivo é descentrar a atenção de pormenores que os alunos poderiam facilmente reconhecer, abrindo, assim, o campo de análise e permitindo a emergência de novas ideias e leituras da tarefa proposta. Lampert (2001) alerta igualmente para a importância de escolher o aluno que irá responder em primeiro lugar. Uma escolha judiciosa tem não raro um papel importante no desencadear da discussão. A autora sublinha que a escolha de um aluno que pareça confuso ou alheado, e que, por exemplo, não tenha tomado a iniciativa de pedir a palavra, pode ajudar a vincar a ideia de que todos os contributos são importantes e que, de uma forma ou de outra, todos são chamados à discussão. De igual modo, esta opção pode contribuir para que todos os alunos possam acompanhar a discussão e participar nela ativamente.

Stein et al. (2008) propõem um conjunto de práticas para os professores dinamizarem uma discussão matematicamente produtiva. Aquando da preparação da aula, o professor antecipa possíveis estratégias de resolução da tarefa preparada e elenca as dificuldades expectáveis. Durante a fase de realização da tarefa, o professor monitoriza o trabalho dos alunos ouvindo-os no sentido de conhecer as diferentes abordagens seguidas e as dificuldades sentidas. Este conhecimento, apoiado na preparação prévia do professor, permite que selecione e sequencie as resoluções para discussão. Durante a fase de discussão, o professor promove o inter-relacionamento de resoluções e conceitos. Em consonância com estas autoras, Menezes et al. (2015), no quadro da caracterização do ensino exploratório, identificam, na fase de discussão da tarefa, um conjunto de ações do professor, associadas a diversas intenções que visam o sucesso dessa fase da aula exploratória.

Um primeiro grupo de elementos desse conjunto relaciona-se com a promoção da aprendizagem matemática. Este inclui a promoção da qualidade matemática das apresentações dos alunos e a regulação das interações entre estes. Pedir aos alunos explicações claras das resoluções e justificações sobre os resultados e as formas de representação utilizadas, discutir a diferença e eficácia matemática das diferentes resoluções apresentadas, por exemplo, contribuem diretamente para a desenvolvimento da qualidade matemática das apresentações. Com o intuito de regular as interações entre os alunos na discussão, Menezes et al. (2015) referem o incentivo ao questionamento para clarificação de ideias apresentadas ou esclarecimento de dúvidas, e o incentivo à análise, confronto e comparação entre resoluções. 
Menezes et al. (2015) identificam um conjunto de ações que permitem operacionalizar a intenção de criar um ambiente propício à apresentação e discussão de ideias e/ou estratégias de resolução. Sublinhamos aqui algumas dessas ações. Por exemplo, o professor deve identificar o momento apropriado para terminar a fase de resolução da tarefa pelos alunos, decidindo se deve esperar pelos que ainda não terminaram a tarefa ou se a fase de discussão que se segue ajudará quem ainda não terminou a resolução a encontrar sentido nas resoluções apresentadas. Outra ação importante prende-se com a reorganização dos lugares/espaço para a discussão, passando de um momento de trabalho em pares ou pequenos grupos (que exige uma certa arrumação na sala de aula) para um momento de discussão em coletivo (para o qual a disposição dos alunos à volta das mesas pode não ser a mais conveniente). Essencial ainda é a promoção de uma atitude, nos alunos, de respeito e interesse genuíno pelos diferentes trabalhos apresentados, condição necessária para que os alunos possam aprender uns com os outros.

Dada a natureza fortemente interativa da discussão, torna-se ainda importante gerir as relações entre os alunos. A discussão ganha corpo através da seleção das resoluções a apresentar e da definição da ordem dessas apresentações. Neste sentido, é importante que o professor ajude o coletivo da turma a compreender que nem todas as resoluções devem ser apresentadas (embora todos os alunos devam participar na discussão), evitando repetições desnecessárias e procurando que, de uma apresentação para a seguinte, seja visível uma evolução de ideias matemáticas ou de estratégias de resolução (no sentido da maior eficiência).

O planeamento e a orquestração de discussões matemáticas na aula põem em evidência a figura do professor, o seu conhecimento didático (Ponte, 2012) e a sua arte de ensinar. Promover discussões levando os alunos a construir conhecimento matemático significa ser capaz de entrelaçar muitos fios de pensamento que cada um dos participantes vai tecendo. Para isso, sendo essencial o professor possuir conhecimento matemático, é igualmente importante compreender como os alunos aprendem e quais as melhores formas de o fazer. E para o fazer de acordo com o que temos vindo a defender, a comunicação como interação social ganha especial centralidade na prática letiva do professor.

\section{Considerações finais}

Neste texto apresentamos duas ideias fortes para a aula de Matemática. Por um lado, a comunicação como interação social enquanto um caminho para a construção do conhecimento matemático pelos alunos. Por outro lado, o ensino exploratório da Matemática como um meio privilegiado para dar corpo a esta conceção de comunicação. Esta conceção assenta numa visão da produção e difusão do conhecimento 
matemático que tem um paralelo próximo na construção do conhecimento tanto na Ciência como na vida quotidiana das pessoas.

Neste sentido, propomos uma vida para a sala de aula de Matemática mais natural, mais próxima da vida dos alunos quando buscam soluções para os problemas com que se confrontam, discutindo com os outros e, por essa via, construindo conhecimento (matemático). Será que a tendência para a escola inverter o sentido deste processo de construção de conhecimento não estará na base de parte do insucesso da aprendizagem da Matemática? Estaremos verdadeiramente a levar os alunos a construir conhecimento matemático quando os conduzimos apenas através da transposição do conhecimento matemático já construído? Ao invés, ao tomarmos a comunicação como expressão genuína do conhecimento de cada um, não estaremos a dar liberdade ao aluno (e ao professor) para construírem um conhecimento matemático sustentado e aprendido com significado?

Neste processo de naturalização da Matemática, o professor é quem traz (é quem pode trazer) para dentro da sala de aula a essência da Matemática e dos seus processos de produção. É também alguém que traz (e pode trazer) a vida exterior para a aula de Matemática e que gere tudo isso, conjugando um conhecimento milenar com a experiência presente de cada aluno. Se habitualmente conversamos fora da sala de aula, observando, ouvindo, questionando, explicando, por que razão não o fazer na aula de Matemática? Comunicar genuinamente, como quem quer saber, e aprender, é uma realidade ainda algo distante de algumas aulas de Matemática. Como mostrámos neste texto, apesar dos desafios que este caminho coloca ao professor de Matemática, ele é viável e tem claras vantagens para a aprendizagem matemática dos alunos.

\section{Agradecimentos}

Este trabalho foi realizado no âmbito do Projeto Práticas Profissionais dos Professores de Matemática (contrato PTDC/CPE-CED/098931/2008), financiado por fundos nacionais através da FCT - Fundação para a Ciência e a Tecnologia.

Rosa Antónia Tomás Ferreira foi parcialmente apoiada pelo CMUP (UID/MAT/00144/2013), financiado pela FCT, com fundos estruturais nacionais (MEC) e internacionais (FEDER), ao abrigo do acordo PT2020.

Luís Menezes foi parcialmente apoiado pelo Instituto Politécnico de Viseu através do Centro de Estudos em Educação, Tecnologias e Saúde (CI\&DETS).

Maria Helena Martinho foi adicionalmente apoiada pela bolsa de sabática SFRH/ BSAB/113585/2015. 


\section{Referências}

Ainley, J. (1988). Perceptions of teachers' questioning styles. Proceedings of PME XII (pp. I, 92-99). Veszprém, Hungary: PME.

Antão, J. (2001). Comunicação na sala de aula. Porto: Edições Asa.

Bauersfeld, H. (1994). Theoretical perspectives on interaction in the mathematics classroom. In R. Biehler, R. Scholz, R. Sträßer \& B. Winkelmann (Eds.), Didactics of mathematics as a scientific discipline (pp. 133-146). Dordrecht: Kluwer Academic Pub.

Beaudichon, J. (2001). A comunicação. Processos, formas e aplicações. Porto: Porto Editora.

Bishop, A., \& Goffree, F. (1986). Classroom organization and dynamics. In B. Christiansen, A. Howson \& M. Otte (Eds.), Perspectives on mathematics education (pp. 309-365). Dordrecht: D. Reidel.

Callahan, K. (2011). Listening responsively. Teaching Children Mathematics, 18(1), 286-305.

Canavarro, A. P. (2011). Ensino exploratório da Matemática: Práticas e desafios. Educação e Matemática, 115, 11-17.

Canavarro, A., Oliveira, H., \& Menezes, L. (2012). Práticas de ensino exploratório da matemática: O caso de Célia. In L. Santos (Ed.), Investigação em Educação Matemática 2012: Práticas de ensino da Matemática (pp. 255-266). Portalegre, Portugal: SPIEM.

Cengiz, N., Kline, K., \& Grant, T. J. (2011). Extending students' mathematical thinking during whole-group discussions. Journal of Mathematics Teacher Education, 14, 355-374.

Coles, A. (2001). Listening: A case study of teacher change. In M. van Heuvel-Panhuizen (Ed.), Proceedings of the 25th Annual Meeting of the International Group for the Psychology of Mathematics Education (Vol. 2, pp. 281-288). Utrecht, The Netherlands: Freudenthal Institute.

Corrêa, R. (2005). Linguagem matemática, meios de comunicação e Educação Matemática. In A. Nacarato \& C. Lopes (Orgs) Escritas e leituras na Educação Matemática (pp. 93-100). Belo Horizonte, Brasil: Autêntica.

Davis, B. (1996). Teaching mathematics: Towards a sound alternative. New York: Garland.

Davis, B. (1997). Listening for differences: An evolving conception of mathematics teaching. Journal for Research in Mathematics Education, 28(3), 355-376.

Dillon, J. T. (1994). Using discussions in classroom. Buckingham Philadelphia: Open University Press.

Duval, R. (2006). Quelle sémiotique pour l'analyse de l'activité et des productions mathématiques? Relime, Número Especial, 45-81.

Eco, U. (1997). O Signo. Lisboa: Editorial Presença.

Eco, U. (2002). Tratado geral de semiótica. São Paulo: Perspetiva.

Fiske, J. (2005). Introdução ao estudo da comunicação. Porto: Edições Asa.

Freixo, M. (2006). Teorias e modelos de comunicação. Lisboa: Instituto Piaget.

Godino, J. (2002). Un enfoque ontológico y semiótico de la cognición matemática. Recherches en Didactique dês Mathématiques, 22(2,3), 237-284. 
Godino, J., \& Llinares, S. (2000). El interaccionismo simbólico en educación matemática. Revista Educación Matemática, 12(1), 70-92.

Guerreiro, A. (2011). Comunicação no ensino-aprendizagem da matemática: Práticas no 1.ํociclo do ensino básico (Tese de Doutoramento, Universidade de Lisboa).

Habermas, J. (1998). O discurso filosófico da modernidade. Lisboa: Publicações Dom Quixote.

Hintz, A. (2011). Understanding students' experiences as listeners during mathematical discussions. Canadian Journal of Science, Mathematics and Technology Education, 11(3), 261-272.

Joly, M. (2005). A imagem e os signos. Lisboa: Edições 70.

Lampert, M. (2001). Teaching problems and the problems of teaching. New Haven, CT: Yale University Press.

Lasswell, H. (2009). A estrutura e a função da comunicação na sociedade. In J. Esteves (Org.) Comunicação e sociedade (pp. 51-62). Lisboa: Livros Horizonte.

Leinhardt, G. (2001). Instructional explanations: A common place for teaching and location for contrast. In V. Richardson (Ed.), Handbook of research on teaching (pp. 333-357). Washington DC, USA: American Educational Research Association.

Mason, J. (1998). Asking mathematical questions mathematically. Actes du Colloque DIDIREM, Réussites et/ou apprentissages Nouvelles technologies; Les mathématiques en premier cycle universitaire, où en est-on? Université de Versailles. [disponível em http://www.math. jussieu.fr/ jarraud/colloque/mason.pdf]

Mason, J. (2000). Asking mathematical questions mathematically. International Journal of Mathematical Education in Science and Technology, 31(1), 97-111.

Mason, J. (2010). Effective questioning and responding in the mathematics classroom. [disponível em http://mcs.open.ac.uk/jhm3/Selected\%20Publications/ Effective\%20Questioning\%20 $\& \% 20$ Responding.pdf]

Menezes, L. (1995). Conceções e práticas de professores de matemática: Contributos para o estudo da pergunta (Dissertação de Mestrado, Universidade de Lisboa). Lisboa: APM.

Menezes, L., Guerreiro, A., Martinho, M. H., \& Tomás Ferreira, R. A. (2013). Essay on the role of teachers' questioning in inquiry-based mathematics teaching. Sysiphus, 1(3), 44-75.

Menezes, L., Oliveira, H., \& Canavarro, A. P. (2015). Inquiry-based mathematics teaching: The case of Célia. In U. Gellert, J. Gimenez Rodriguez, C. Hahn \& S. Kafoussi (Eds.), Educational paths to Mathematics (pp. 305-321). Cham: Springer.

Menezes, L., Tomás Ferreira, R., Martinho, M. H., \& Guerreiro, A. (2014). Comunicação nas práticas letivas dos professores de Matemática. In J. P. Ponte (Ed.), Práticas profissionais dos professores de matemática (pp. 135-161). Lisboa: Instituto de Educação.

Nicol, C. (1999). Learning to teach mathematics: Questioning, listening, and responding. Educational Studies in Mathematics, 37(1), 45-66.

Pirie, S., \& Schwarzenberger, R. (1988). Mathematical discussion and mathematical understanding. Educational Studies in Mathematics, 19, 459-470.

Ponte, J. P. (2005). Gestão curricular em Matemática. In GTI (Ed.), O professor e o desenvolvimento curricular (pp. 11-34). Lisboa: APM. 
Ponte, J. P. (2012). Estudiando el conocimiento y el desarrollo profesional del profesorado de matemáticas. In N. Planas (Coord.), Teoría, crítica y práctica de la educación matemática (pp. 83-98). Barcelona, España: Graó.

Rodrigues, A. (1990). Estratégias da comunicação. Questão comunicacional e formas de sociabilidade. Lisboa: Editorial Presença.

Ruthven, K., Hofmann, R., \& Mercer, N. (2011). A dialogic approach to plenary problem synthesis. In B. Ubuz (Ed.), Proceedings of the 35th Conference of the International Group for the Psychology of Mathematics Education (vol. 4, pp. 81-88). Ankara, Turkey: PME.

Sfez, L. (1991). A comunicação. Lisboa: Instituto Piaget.

Sherin, M. G. (2002). A balancing act: Developing a discourse community in a mathematics classroom. Journal of Mathematics Teacher Education, 5, 205-233.

Sierspinska, A. (1998). Three epistemologies, three views of classroom communication: Constructivism, sociocultural approaches, interactionism. In H. Steinbring, M. Bussi \& A. Sierpinska (Eds.), Language and communication in the mathematics classroom (pp. 30-62). Reston: NCTM.

Stein, M. K. (2001). Mathematical argumentation: Putting umph into classroom discussions. Mathematics Teaching in the Middle School, 7(2), 110-112.

Stein, M. K., \& Smith, M. S. (1998). Mathematical tasks as a framework for reflection: From research to practice. Mathematics Teaching in the Middle School, 3, 268-275.

Stein, M. K., Engle, R. A., Smith, M. S., \& Hughes, E. K. (2008). Orchestrating productive mathematical discussions: Helping teachers learn to better incorporate student thinking. Mathematical Thinking and Learning, 10(4), 313-340.

Tomás Ferreira, R. A. (2005). Portuguese mathematics student teachers' evolving teaching modes: A modified teacher development experiment (Tese de Doutoramento, Illinois State University, EUA).

Voigt, J. (1985). Patterns and routines in classroom interaction. Recherches en Didactique des Mathématiques, 6(1), 69-118.

Recebido em: 18/11/2015

Aprovado em: 21/12/2015 